\title{
“Não Converso com Demente”: Intersecções entre Direito e Saúde Mental
}

\author{
Sandra Maciel de Carvalho \\ Universidade Federal de Juiz de Fora, Juiz de Fora, \\ MG, Brasil.
}

\author{
Juliana Perucchi \\ Universidade Federal de Juiz de Fora, Juiz de Fora, \\ MG, Brasil.
}

Resumo: Neste artigo apresenta-se a análise do discurso foucauldiana de enunciados de um dos processos judiciais que compuseram uma dissertação de Mestrado em Psicologia da Universidade Federal de Juiz de Fora (MG). A gênese da pesquisa foi um episódio ocorrido com um usuário de um Centro de Atenção Psicossocial (CAPS), que denunciou sua curadora por maus-tratos e negligência a uma Promotora de Justiça que, mais tarde, recusou-se a recebê-lo afirmando: "Não converso com demente". A pesquisa, de natureza documental, cujo critério de inclusão foi haver diagnóstico de transtorno mental, foi realizada com três processos judiciais de usuários daquele CAPS. Problematizaram-se as posições de sujeito designadas aos usuários pelo discurso da justiça; as associações e/ou articulações entre o diagnóstico de transtorno mental e outros enunciados e a relação entre curatela, inimputabilidade e cidadania. Pode-se afirmar que o discurso jurídico designa posições de sujeito depreciativas para portadores de transtorno mental, respaldando-se no saber/poder médicos para enunciar verdades acerca dos mesmos. A cidadania é negada por meio da interdição e curatela. Há uma distância entre os códigos Civil e de Processo Civil e as propostas da Reforma Psiquiátrica, especialmente no tocante aos direitos dos portadores de transtorno mental.

Palavras-chave: Transtorno Mental, Atenção Psicossocial, Justiça, Análise do Discurso.

\section{“I don't Talk to Lunatics”: Intersections between Law and Mental Health}

\begin{abstract}
This article presents a Foucauldian Discourse Analysis of enunciations regarding one of the judicial processes composing a Master dissertation on Psychology from Universidade Federal de Juiz de Fora (MG). The genesis of the research was the fact that a user from a Center of Psychosocial Attention (CAPS) reported his guardian for negligence and bad-treatment to a Promoter of Justice who, later on, refused to receive him, asserting: "I don't talk to lunatics". The research, of documentary nature, whose inclusion criterion was being a filed investigation record dealing with a diagnosis of mental disorder, was held with three judicial processes from users of the CAPS above mentioned. Subject positions that are assigned by the legal discourse to people with mental disorders were discussed, as well as the relationship between the diagnosis of mental disorder and another enunciations, and the relation among guardianship, non-imputability and citizenship. It is possible to affirm that legal discourse designates derogatory subject positions to people with mental disorder, supported by medical knowledge/power to enunciate truths about them. Citizenship is denied through processes of interdiction and guardianship. There is a gap between the Civil Code and the Civil Process Code, and the proposals of the Psychiatry Reform, especially regarding the rights of people with mental disorder.
\end{abstract}

Keywords: Mental Disorder, Psychosocial Care, Justice, Discourse Analysis. 


\title{
“No Hablo con Dementes": Intersecciones entre el Derecho y la Salud Mental
}

\begin{abstract}
Resumen: En este artículo se presenta un análisis foucauldiano del discurso hacia los enunciados de uno de los procesos judiciales que componen una tesis de Maestría en Psicología de la Universidade Federal de Juiz de Fora (MG). La génesis de la investigación fue lo ocurrido a un usuario de un Centro de Atenção Psicossocial (CAPS), que denunció a su curadora por malos tratos y negligencia ante una Promotora de Justicia que, más tarde, se negó a recibirlo afirmando: "No hablo con dementes". La pesquisa basada en fuentes de investigación documental, cuyo criterio de inclusión fue ser un expediente archivado relacionado con diagnóstico de trastorno mental, fue realizada en tres procesos judiciales de usuarios de dicho CAPS. A través de esta investigación se cuestionaron las posiciones de los sujetos asignados, por parte del discurso de la justicia, a los usuarios del CAPS; también, las asociaciones y/o articulaciones entre el diagnóstico de los trastornos mentales y otras enunciaciones, así como la relación entre la interdicción, la inimputabilidad y la ciudadanía. Se puede afirmar que el discurso jurídico designa posiciones de sujeto despectivas para los enfermos mentales, apoyándose en el conocimiento/poder médico para enunciar verdades a cerca de ellos. La ciudadanía es negada por medio de la interdicción y tutela. Hay un alejamiento entre el Código Civil y el Procedimiento Civil, y las propuestas de la reforma psiquiátrica, especialmente con respecto de los derechos de los enfermos mentales.

Palabras clave: Trastorno Mental, Atención Psicosocial, Justicia, Análisis del Discurso.
\end{abstract}

\section{Introdução}

Este artigo é fruto de pouco mais de uma década de trabalho como psicóloga junto a pessoas com transtorno mental, em um Centro de Atenção Psicossocial (CAPS), em Minas Gerais. A população atendida pela instituição é composta majoritariamente por pessoas com diagnóstico de psicose, que trazem as mais diversas questões: desde problemas concretos da vida cotidiana, como a parede da casa em que reside estar ruindo, até a angústia de ser "perseguido no ônibus por alguém que quer matá-lo após ter queimado seu pulmão, pelo fato de pertencer a um sindicato". Recorrem aos profissionais muitas vezes para auxiliá-los na resolução de problemas com familiares e, em grande parte dos casos, as soluções se tornam complexas em função de ter havido uma interdição judicial e de ser o curador, exatamente, a pessoa de quem o usuário do CAPS se queixa.

A interdição judicial é o processo que se destina a reconhecer legalmente que alguém é incapaz de praticar os atos da vida civil. Essa incapacidade pode se dar por diferentes motivos, desde a menoridade até o transtorno mental. Nos casos de transtorno mental, a incapacidade deve ser comprovada por meio de um dispositivo médico-jurídico (o exame pericial) e pela arguição pessoal do interditando, realizada pelo Juiz de Direito. Uma vez considerado incapaz ou parcial- mente incapaz, o juiz nomeia um curador que tem as funções de representar o interdito nos atos circunscritos pela interdição e de cuidar de seus interesses, estendendo-se estes à sua saúde e bem-estar. O Ministério Público (MP) é o responsável pela fiscalização do processo e do curador.

Foi uma tentativa de se recorrer ao MP para tentar resolver as queixas de negligência e maus-tratos de um usuário do CAPS em relação à sua curadora que fecundou a inquietação da autora sobre as relações entre justiça e saúde mental. A equipe e o usuário denunciaram-na após tentativas vãs de resolverem a questão com diálogos entre as partes, intermediados pelo CAPS. Segundo relato do usuário, a curadora negava-lhe qualquer tipo de cuidado, chegando mesmo a dormir na rua enquanto a família usufruía de seu benefício. Entre o envio de ofícios, a realização de visitas aos gabinetes de Promotores de Justiça, arquivamentos e realização de novas denúncias, o caso se arrasta há anos na justiça. A cada troca de Promotor, reacende a esperança do usuário e dos profissionais de que essa questão seja solucionada. O primeiro arquivamento da denúncia desse caso não foi sequer comunicado ao CAPS e/ou ao usuário, e ele e a equipe só tomaram conhecimento do fato depois de entrarem em contato com o MP novamente, devido à enorme demora em obter resposta. 
Informado da possibilidade de marcar uma audiência com a operadora do direito e, na esperança de que, ao ouvir sua narrativa dos fatos, ela se sensibilizasse e decidisse trabalhar no caso novamente, o usuário acompanhado da assistente social do serviço se dirigiu ao fórum. Depois de esperarem algumas horas além do horário marcado, surpreendentemente, a profissional foi convidada a entrar sozinha no gabinete da Promotora. Tendo insistido com a operadora do direito na presença do usuário, afinal, ele era a vítima, como resposta - segundo a assistente social - a Promotora lhe afirmou: "Não converso com demente". Esta frase configurou-se uma inquietação constante para a autora/psicóloga do CAPS, relembrada em cada ocasião na qual um usuário do serviço necessitava recorrer à justiça a fim de tentar garantir seus direitos e acabou por se transformar em um problema de pesquisa de Mestrado em Psicologia: investigar as relações estabelecidas pela justiça e as pessoas com transtornos mentais, usuárias de serviços de saúde pública.

Segundo Albuquerque (1986), as práticas dos que têm função de palavras na justiça podem ter um efeito repressivo direto, fazendo calar ou apagando pela palavra argumentos ou partes de um discurso que não deve ser considerado. $O$ episódio acima descrito ilustra adequadamente essa afirmativa. De fato, a Promotora foi além de fazer calar ou apagar partes do discurso, ela sequer permitiu que o usuário falasse, como um efeito repressivo direto de sua prática. Para Foucault (1996), as práticas judiciárias estão entre as mais importantes em que a análise histórica permite localizar a emergência de novas formas de subjetividade e de saber, sendo possível, através do estudo da prática penal, compreender como formas de verdade podem ser definidas.

No Brasil, dois dos principais códigos jurídicos em vigor são: o Código Civil (CC) e o Código de Processo Civil (CPC). O primeiro regula os direitos e as obrigações de ordem privada das pessoas, dos bens e de suas relações, e o CPC é aquele que regulamenta o exercício da jurisdição quanto às lides de natureza civil, incluindo a interdição e curatela. O primeiro CC, de 01 de janeiro de 1916, sofreu uma reformulação que data de 10 de Janeiro de 2002 e, no que tange à saúde mental, traz como diferença do texto anterior apenas a possibilidade de interdição parcial e não mais obrigatoriamente total dos "absolutamente incapazes" de manter atos da vida civil, "os deficientes mentais" que não tiverem o necessário discernimento para prática desses atos.
Nessa reformulação, as mudanças propostas em relação aos direitos dos portadores de transtorno mental perpassaram mais à semântica das palavras do que à essência da lei, mesmo tendo decorrido um espaço de tempo de 86 anos. Os processos histórico-sociais que culminaram em um contexto muito diverso daquele em que foi redigido o antigo Código e que determinaram transformações na área da saúde parecem ter sido ignorados. $\mathrm{O}$ artigo mais significativo nesta direção é o:

Art. 1.777. Os interditos referidos nos incisos I [aqueles que, por enfermidade ou deficiência mental, não tiverem o necessário discernimento para os atos da vida civil], III [os deficientes mentais, os ébrios naturais e os viciados em tóxicos], e IV [os excepcionais sem completo desenvolvimento mental] do art. 1.767 serão recolhidos em estabelecimentos adequados, quando não se adaptarem ao convívio doméstico (Brasil, 2002).

Nota-se que o legislador manteve a proposta asilar do antigo CC: "Art. 457. Os loucos, sempre que parecer inconveniente conservá-los em casa, ou o exigir o seu tratamento, serão também recolhidos em estabelecimento adequado" (Brasil, 1916). Houve apenas a substituição da "inconveniência de tê-los por perto" pela "não adaptação" dos portadores de transtorno mental à família, mas o "recolhimento em estabelecimento adequado" foi mantido. Ressalta-se que esse artigo caminha em direção oposta à Lei no ${ }^{\circ} 10.216 / 01$, publicada no DOU em 09 de abril de 2001, quando passou a vigorar:

Art. 30. É responsabilidade do Estado o desenvolvimento da política de saúde mental, a assistência e a promoção de ações de saúde aos portadores de transtornos mentais, com a devida participação da sociedade e da família, a qual será prestada em estabelecimento de saúde mental, assim entendidas as instituições ou unidades que ofereçam assistência em saúde aos portadores de transtornos mentais.

Art. $4^{\circ}$. A internação, em qualquer de suas modalidades só será indicada quando os recursos extra-hospitalares se mostrarem insuficientes. $\$ 1^{\circ} \mathrm{O}$ tratamento visará, como finalidade permanente, a reinserção social do paciente em seu 
meio. [...] § $3^{\circ}$ É vedada a internação de pacientes portadores de transtornos mentais em instituições com características asilares, ou seja, aquelas desprovidas dos recursos mencionados no $\$ 2^{\circ} \mathrm{e}$ que não assegurem aos pacientes os direitos enumerados no parágrafo único do art. $2^{01}$ (Brasil, 2001).

Em relação ao exercício da tutela e curatela, a legislação prevê o privilégio para os "reconhecidamente idôneos" de iniciar o exercício da tutela ou curatela sem prestar garantia da "especialização em hipoteca legal de imóveis necessários para acautelar os bens que serão confiados à sua administração", prevista no artigo 1.188, ou mesmo sendo dispensados dela, como se lê no artigo 1.190, ambos do CPC: "Art. 1.190. Se o tutor ou curador for de reconhecida idoneidade, poderá o juiz admitir que entre em exercício, prestando depois a garantia, ou dispensando-a desde logo"73). Necessário se faz questionar: o que torna uma pessoa "reconhecidamente idônea" para ocupar uma posição de sujeito privilegiada pelo CPC? Sem critérios claros para definir legalmente o que seja "idoneidade reconhecida", aqueles que ocupam essa posição de sujeito, designada pela justiça, exercem um poder extremo, já que a lei a eles se curva. A sentença que declara a interdição é imediata, segundo o artigo 1.773 do CC e está sujeita a recurso, o que acena para uma possibilidade de resistência por parte do tutelado ou curatelado.

Observa-se que a legislação não esclarece como esse recurso deve ser interposto e qual o prazo, o que dificulta a possibilidade de exercer resistência, já que, possivelmente, a busca por essa informação consumirá certo tempo, que pode ser igual ou superior àquele do prazo do recurso. Essa condição do tutelado ou curatelado é contrária à que preconiza o CPC para o tutor ou curador: "Art. 1.192. O tutor ou curador poderá eximir-se do encargo, apresentando escusa ao juiz no prazo de 5 (cinco) dias", bem como no seu artigo 1.198 que permite ao tutor ou curador que, uma vez tendo cessado suas funções "pelo decurso do prazo em que era obrigado a servir, ser-lhe-á lícito requerer a exoneração do encargo; não o fazendo dentro dos 10 (dez) dias seguintes à expiração do termo, entender-se-á reconduzido, salvo se o juiz o dispensar".

Há um artigo do novo CC cuja modificação é considerada, em diferentes literaturas sobre o tema da interdição ${ }^{2}$, como um avanço na legislação concernente aos portadores de transtorno mental:

Art. 1.772. Pronunciada a interdição das pessoas que se referem os incisos III e IV do art. 1.767, o juiz assinará, segundo o estado ou o desenvolvimento mental do interdito, os limites da curatela, que poderão circunscrever-se às restrições constantes do art. 1.782. (Brasil, 2002).

É importante esclarecer que o CPC já previa a possibilidade de se limitar a curatela, em seu artigo 1.184:

A sentença de interdição produz efeito desde logo, embora sujeita a apelação. Será inscrita no Registro de Pessoas Naturais e publicada pela imprensa local e pelo órgão oficial por três vezes, com intervalo de 10 (dez) dias, constando do edital os nomes do interdito e do curador, a causa da interdição e os limites da curatela (Brasil, 1973.)

Em 2010, uma comissão de juristas elaborou o Anteprojeto de Código de Processo Civil com o desafio, segundo o Ministro Luiz Fux, Presidente da Comissão encarregada da elaboração, "de resgatar a crença no judiciário e tornar realidade a promessa constitucional de uma justiça pronta e célere" (Brasil,

\footnotetext{
1 “Art. $2^{\text {o }}$. Nos atendimentos em saúde mental, de qualquer natureza, a pessoa e seus familiares ou responsáveis serão formalmente cientificados dos direitos enumerados no parágrafo único deste artigo. Parágrafo único. São direitos da pessoa portadora de transtorno mental: I - ter acesso ao melhor tratamento do sistema de saúde, consentâneo às suas necessidades; II - ser tratada com humanidade e respeito e no interesse exclusivo de beneficiar sua saúde, visando alcançar sua recuperação pela inserção na família, no trabalho e na comunidade; III - ser protegida contra qualquer forma de abuso e exploração; IV - ter garantia de sigilo nas informações prestadas; V ter direito à presença médica, em qualquer tempo, para esclarecer a necessidade ou não de sua hospitalização involuntária; VI - ter livre acesso aos meios de comunicação disponíveis; VII - receber o maior número de informações a respeito de sua doença e de seu tratamento; VIII - ser tratada em ambiente terapêutico pelos meios menos invasivos possíveis; IX - ser tratada, preferencialmente, em serviços comunitários de saúde mental” (Brasil, 2001).

${ }^{2}$ Nesse sentido, ver a “Apresentação III” do livro “A banalização da interdição judicial no Brasil - relatórios”, (Brasil, 2007), e a cartilha do Instituto Franco Basaglia, intitulada "Conversando com o Ministério Público: O Ministério Público e a Reforma Psiquiátrica", pergunta 4.1, p. 15 (Instituto Franco Basaglia, 2004).
} 
2010, p. 7). No que diz respeito à interdição e curatela, o Anteprojeto manteve as mesmas bases do CPC em vigor, com uma única modificação, constante do artigo 682: "Parágrafo único. Não podendo o interditado deslocar-se, o juiz o ouvirá e examinará no local onde estiver" (Brasil, 2010, p. 203).

Dessa forma, o único "avanço" proposto pela Comissão para os portadores de transtorno mental e demais pessoas sujeitas à interdição e curatela foi o fato de poderem ser ouvidos onde estiverem devido à precariedade de suas condições de saúde. Uma vez que o CPC regulamenta o exercício da jurisdição quanto às lides do $\mathrm{CC}$ e, tendo este mantido praticamente os mesmos artigos referentes à interdição e curatela do Código de 1916, continua uma defasagem histórica dos portadores de transtorno mental enquanto sujeitos de direitos.

Considerando-se os dois cenários (dos serviços públicos de saúde mental que devem trabalhar na lógica antimanicomial e o do direito), bem como a realidade empírica do CAPS mencionado neste artigo, no qual há uma série de processos envolvendo usuários que tramitam há anos na justiça, a autora realizou, no Mestrado em Psicologia da Universidade Federal de Juiz de Fora (UFJF), uma pesquisa documental de processos judiciais. O objetivo geral da pesquisa foi analisar por meio da análise do discurso foucauldiana os enunciados que ocorrem em processos judiciais que envolvem pessoas com diagnóstico de transtorno mental, usuárias do CAPS acima citado, problematizando as posições de sujeito designadas a tais pessoas nos discursos da justiça por meio de dispositivos de saber-poder. Como objetivos específicos, buscou-se analisar: como se processa a relação entre curatela, inimputabilidade e cidadania? A quais enunciados o diagnóstico de transtorno mental pode associar-se e/ou articular-se em um processo judicial?

A dissertação foi composta por três processos judiciais, sendo apresentada, neste artigo, a análise do processo de interdição e curatela, que foi a gênese da pesquisa. Em diálogo com a fundamentação teórica que subsidia reflexão, retomam-se as proposições de Foucault (2007) que afirma que lançar mão de documentos como matéria-prima de análise permite "decifrar as relações de poder, de dominação e de luta dentro das quais os discursos se estabelecem e funcionam; o que permite, assim, uma análise do discurso ao mesmo tempo política e relacionada com o acontecimento; logo, estratégica" (Foucault, 2007, p. XIII).

\section{Método}

Com base na perspectiva teórica da análise do discurso foucauldiana, realizou-se uma pesquisa documental, na qual foram analisados os enunciados que ocorrem em processos judiciais civis e criminais e que envolvem usuários do CAPS, problematizando as posições de sujeito designadas a eles, nos discursos da justiça, por meio de dispositivos de saber/poder.

Segundo a Constituição Federal e o CPC, o acesso aos processos é livre, sendo os mesmos considerados públicos. O projeto de pesquisa foi submetido e aprovado pela Comissão Nacional de Ética em Pesquisa (Conep) sob o número 09162313.4.0000.5147. A pesquisa iniciou-se com autorização da coordenadora do CAPS nos prontuários ativos na instituição, que totalizaram 159. O objetivo neste primeiro momento foi buscar documentos que evidenciassem qualquer tipo de envolvimento dos usuários com a justiça. Dos 159, 17 prontuários continham documentos ou cópias de documentos que evidenciavam o envolvimento dos usuários com o Poder Judiciário. A soma destes documentos resultou em 118, sendo eles: ofícios, mandados de intimação, relatórios sociais, pesquisas de andamento de processo, certidões, termos de depoimento, homologação de sentença, dentre outros, trazidos pelos próprios usuários ou familiares ou enviados diretamente para o CAPS pela justiça. Esses documentos foram digitalizados por meio de uma impressora e, em seguida, iniciou-se a organização do arquivo da pesquisa em uma tabela, na qual cada usuário foi identificado por um código e, a cada tipo de documento encontrado em seu prontuário, foi dado um símbolo, de acordo com sua natureza. A partir daí, foi criada uma legenda para o quadro, constituído por 38 diferentes tipos de documentos. Na sequência, consultou-se o site do Tribunal de Justiça de Minas Gerais (TJMG), pela pesquisa com o nome completo da parte, confirmando-se a existência dos processos aos quais os documentos se referiam e descobrindo-se outros nos quais os mesmos usuários eram parte. Em seguida, foi realizada a primeira inserção no campo, com o objetivo da leitura dos processos e ambientação com a instituição e os funcionários do fórum.

Em um segundo momento, foi solicitada a autorização dos juízes das diferentes varas para se proceder a cópia dos documentos e cada escrivão responsável, por uma das secretarias, recebeu uma cópia do deferimento da solicitação. Os primeiros processos foram 
reproduzidos por intermédio de uma copiadora, mas, aliando o alto custo e a baixa qualidade de algumas cópias, optou-se por digitalizar os demais processos através de um tablet, fotografando em alta resolução cada página.

Da lista inicial de 118 documentos constantes nos prontuários do CAPS e com a consulta ao site do TJMG, chegou-se a 43 conjuntos de documentos: sete ofícios do MP e 36 processos judiciais. Em seguida, estabeleceram-se os critérios de inclusão e exclusão das fontes documentais: foram excluídos os documentos do MP, por não se tratarem de processos judiciais; os processos judiciais que continham documentos cujos conteúdos foram formulados pela pesquisadora ou que incluíam sua participação como membro da equipe do CAPS (como respostas a ofícios enviados pelo Judiciário e pareceres solicitados pelo MP); os que não referiam diagnóstico de transtorno mental; os que estavam ativos (em trâmite) e os que estavam sob segredo de justiça. Os critérios de inclusão foram, portanto, processos judiciais nos quais havia diagnóstico de transtorno mental de pessoas usuárias do CAPS, baixados definidamente.

Dos 36 processos, um se referia a dois usuários do CAPS, sendo eles a vítima e testemunha, o que reduziu o número para 35 processos. Desses, um estava na Delegacia de Polícia (Depol), reduzindo o número para 34 processos. Dos 34, 15 foram excluídos em função de ainda não terem sido encerrados à época do trabalho de campo. Dos outros 19 processos baixados definitivamente, um continha um atestado emitido pela pesquisadora e quatro não tinham menção a diagnóstico de transtorno mental e foram, portanto, excluídos. Logo, chegou-se ao um número de 14 processos e seus apensos (processos que derivam do processo original) que somaram mais de 2.300 páginas. Em função do grande número de documentos a pesquisa contemplou, inicialmente, um processo de cada uma das varas do fórum da Comarca em questão: Criminal, 1 ${ }^{\text {a }}$ Vara Cível, 2a Vara Cível e Juizado Especial Criminal. Excluíram-se a Vara da Família, Infância e da Juventude e Precatórias, por não constar processo baixado definitivamente à época da pesquisa e o Juizado Especial Cível, cujos processos não mencionavam diagnóstico de transtorno mental. Contudo, no decorrer das análises dos processos, que demandaram um estudo crite- rioso dos códigos jurídicos e demais legislações, descobriu-se que o processo do Juizado Especial Criminal deveria ter corrido sob segredo de justiça; tendo sido ele, portanto, excluído também.

Após os procedimentos de inclusão/exclusão dos processos, iniciou-se a leitura de cada um deles, destacando-se categorias de análise (posições de sujeito designadas aos usuários pelo discurso jurídico) bem como informações como datas, instituições, cidades, natureza do documento e posições de sujeito dos demais envolvidos nos processos. Cada uma destas informações recebeu uma cor diferente, de forma que pudesse ser facilmente reconhecida no manuseio dos documentos. Os nomes de todos os envolvidos nos processos foram substituídos, de forma que suas identidades fossem preservadas.

As análises foram realizadas por meio da análise do discurso de referencial foucauldiano que, segundo o autor:

trata-se de compreender o enunciado na estreiteza e singularidade de sua situação; de determinar as condições de sua existência, de fixar seus limites da forma mais justa, de estabelecer suas correlações com os outros enunciados a que pode estar ligado, de mostrar que outras formas de enunciação exclui (Foucault, 2010, p. 31).

A afirmativa da Promotora de Justiça "Não converso com demente" é um claro exemplo de uma formação discursiva na qual se pode constatar a designação das posições de sujeito em jogo, bem como a hegemonia do discurso do direito designando por meio de estratégias de saber/poder, quem pode (e quem não pode) exercer o direito à palavra perante a justiça.

A análise que o leitor poderá acompanhar neste artigo será, exatamente, a do processo do usuário designado como "demente" pela Promotora de Justiça, aqui denominado Douglas. Seu processo de Interdição e Curatela, da $2^{\text {a }}$ Vara Cível, tendo sido a gênese da dissertação, tornou-se emblemático das relações da justiça com os portadores de saúde mental no âmbito da pesquisa realizada. Ademais, não sendo possível apresentar as análises dos três processos constantes da dissertação sem comprometer a discussão dos resultados, optou-se por apresentar apenas este processo ao leitor. 


\section{Resultados}

O processo de interdição e curatela de Douglas foi aberto a pedido de seu irmão unilateral (denominado aqui Tiago) oito anos antes do episódio no qual a Promotora de Justiça negou-se a recebê-lo em seu gabinete, designando-o "demente". Nos próximos parágrafos, o processo será apresentado com a transcrição dos principais trechos que contribuem para a análise documental.

Por meio da Defensoria Pública, Tiago requereu a interdição e curatela de Douglas, alegando que:

[...] O Paciente sofre de doença mental e seus atos do cotidiano revelam incapacidade para reger sua própria pessoa e administrar seus bens, estando internado inclusive na Clínica X Ltda. [...] requer a Vossa Excelência se digne de mandar citar o Interditando para [...], comparecer a este Juízo para seu exame e interrogatório, [...] e procedido o exame médico por perito nomeado, deverá a presente ser processada e, a final, julgada procedente, decretada a interdição de Douglas, e lhe nomeando Curador o próprio Promovente, na forma e para fins de Direito.

Os documentos que vêm a seguir no processo são o "Atestado de Internação e Alta" da "Clínica X Ltda" de "Doenças Nervosas e Mentais - Clínica de Repouso", no qual se lê que Douglas havia sido internado quinze dias antes do pedido de Interdição e Curatela por tempo indeterminado; e a "Certidão de Nascimento" de Douglas, nascido em 1969, e que data de seis meses antes do pedido de Interdição e Curatela.

O Juiz de Direito ordena, na sequência, que se marquem duas audiências e que os irmãos sejam intimados. Em ambas as ocasiões, os dois não compareceram, em função de Tiago não ter sido localizado pelo oficial de justiça. Marca-se uma terceira audiência, na qual Douglas comparece e é atribuído a ele o seguinte trecho de narrativa constante no "Interrogatório Pessoal do Interditando":

que inquirido pelo Juiz nada respondeu, que o depoente residia na cidade de $\mathrm{Z}$ e atualmente reside nesta cidade, que o depoente presenciou o assassinato de sua mãe, quando tinha treze anos de idade, sendo encaminhado posteriormente para a Febem [Fundação Estadual para o Bem-estar do Menor] pelo seu pai, quem assassi- nou a mãe do depoente foi um tal de João que trabalhava na [nome da empresa], que o depoente já trabalhou em um sítio atualmente está parado, que não sabe ler e nem escrever, que não conhece dinheiro, que o depoente chegou a ir somente um dia na aula, que atualmente está morando com o seu irmão; que a tia do depoente jogou o depoente na rua; Que a tia do depoente chama Rita." [...] "Dada a palavra ao Dr. Promotor de Justiça nada quis perguntar. (Grifos da autora).

Logo após, Douglas foi submetido "a exame médico" "no Posto de Saúde do Almoxarifado da Prefeitura Municipal" por ordem judicial. O suposto laudo médico produzido neste exame é um papel timbrado do "Poder Judiciário do Estado de Minas Gerais, Secretaria da Segunda Vara Cível”, assinado por, provavelmente, o profissional designado pelo Juiz para a realização do exame pericial. Nesse documento constam 23 palavras manuscritas que se referem às respostas aos "Quesitos apresentados pelo Requerente", sendo a assinatura ilegível e estando o carimbo profissional apagado. Nele, pode-se ler que Douglas apresenta "Distúrbios psiquiátricos Deficiência Mental (Oligofrenia)", "Psicose Esquizofrênica"; que a "doença" é irreversível, não sendo ele "capaz de reger sua pessoa e bens" "Internações Múltiplas em Clínica Psiquiátrica".

Nove dias depois, o Ministério Público emitiu seu "Parecer":

Tiago [...] requereu a interdição de seu irmão, Douglas [...] O feito seguiu os seus trâmites regulares, tendo o interditando, [...] sido submetido a exame médico-pericial cujo laudo respectivo, foi juntado às fls. 25 [...] De acordo com as conclusões contidas no laudo pericial de fls. 15, o interditando, Douglas, padece de anomalia psíquica, de caráter irreversível, que o torna incapaz de reger sua própria pessoa e administrar seus bens. Aliás, tal fato já ficara evidenciado, quando do seu interrogatório em juízo. Urge, pois, que se lhe dê quem o represente legalmente. Assim sendo [...] o Ministério Público opina no sentido de que se decrete a interdição de Douglas, dando-se-lhe procurador o seu irmão, Tiago, ora requerente.

O Defensor Público, agora representando a tia e não mais o irmão de Douglas, requereu: "continuidade da Interdição e nomeação de Curador para seu 
sobrinho Douglas, pelos motivos de fato e de direito a seguir expostos: [...] 3) - A Requerente é tia materna do Interditando e pretende dar fluência ao processo, até final decisão e sua nomeação como Curadora de Douglas". O Ministério Público não se opôs ao pedido, e o Juiz decidiu:

O ilustre representante do Ministério Público [...] fora favorável à decretação da interdição, considerando que Tiago é pessoa que sofre de anomalia psíquica, de caráter irreversível, que o torna incapaz de reger a sua própria pessoa e administrar seus bens e, ao mesmo tempo, nomeando o promovente curador do mesmo. Entretanto, insurgiu Rita [...] tia materna do interditando [...] alegando, em síntese, que Tiago desapareceu, não dando notícias, razão pela qual pretende dar fluência ao processo, sendo ao final, nomeada Curadora daquele. [...] Este o relatório, decido. [...] verifica-se que o interditando, que realmente sofre de anomalia psíquica, de caráter irreversível, conforme se depara no laudo pericial de fls. 25, precisa de ser-lhe nomeado curador. Assim, como a nova promovente tem legitimidade para estar no polo ativo da presente ação, [...] não vislumbramos nenhum empecilho para tal substituição processual. Ademais, pelo que me consta, o interditando já possui laços afetivos com aquela. Aliás, a nossa melhor doutrina tem entendido desta maneira, valendo citar, por oportuno, a lição de Nélson Nery Júnior e Rosa Maria Andrade Nery [...] que assim se manifestaram: 'Parece-nos que a lei processual exige que, além de ser parente, este tenha com o interditando laços de afetividade e proximidade que o façam capaz de saber das razões que tornaram necessária a medida pleiteada e de compreender da sua conveniência'. É o caso dos autos, indubitavelmente. [...] considerando o que tudo mais dos autos consta, julgo procedente a presente ação, decretando a interdição de Douglas, sendo-lhe nomeada curadora a senhora Rita.

Os procedimentos que se seguem no processo são: expedição e publicação do "Edital de Interdição" no saguão do fórum da Comarca, publicação na Imprensa Oficial e averbação da interdição definitiva à margem do termo de nascimento de Douglas.

\section{Discussão}

Pode-se afirmar que Douglas tem sua posição de sujeito "doente mental" designada já no início do processo pelo irmão e enfatizada em quase todos os momentos em que é enunciado: "sofre de doença mental" (fl. 02), "internado(a) [...] para tratamento Médico Psiquiátrico" (fl. 07); "Apresenta Distúrbios Psiquiátricos Deficiência Mental (Oligofrenia)" (fl. 25); "portador de deficiência mental", "padece de anomalia psíquica” (fl. 29); "sofre de doença mental” (fl. 33); "sofre de anomalia psíquica", "pessoa portadora de anomalia psíquica de caráter irreversível", "sofre de anomalia psíquica de caráter irreversível” (fl. 34); "por sofrer o mesmo das faculdades mentais" (fl. 37 e fl. 39). Torna-se importante ressaltar que a suposta "doença mental" de Douglas estaria comprovada, também, por critérios subjetivos, como a suposta afirmativa de seu irmão na Defensoria Pública, ao requerer sua "Interdição e Curatela": "eis que é irmão do paciente Interditando [...] O Paciente sofre de doença mental e seus atos do cotidiano revelam incapacidade para reger sua própria pessoa e administrar seus bens" e, também, pela avaliação empírica do Promotor de Justiça, relatada no "Parecer do Ministério Público": "padece de anomalia psíquica, de caráter irreversível [...] Aliás, tal fato já ficara evidenciado, quando do seu interrogatório em juízo". O Promotor de Justiça parece tão seguro de sua avaliação que, nesse documento citado, em seu "Parecer" ("Interrogatório Pessoal do Interditando"), pode-se ler: "Dada a palavra ao Dr. Promotor de Justiça nada quis perguntar".

Essa posição de sujeito "doente mental" não é questionada ao longo do processo, ainda que designada a partir de uma suposta afirmação do irmão de Douglas à Defensoria Pública, respaldada por um documento rasurado que comprova sua internação, curiosamente providenciada 15 dias antes do pedido de Interdição e Curatela.

Quando decretada sua interdição judicial e nomeada curadora sua tia, as possibilidades de resistência por parte de Douglas tornam-se escassas. No "Interrogatório Pessoal do Interditando", realizado pelo Juiz de Direito, suas palavras foram anuladas através do objeto direto "nada" que cumpre também a função de, sinteticamente, adjetivar todo o seu depoimento que vem a seguir: "que inquirido pelo Juiz, nada respondeu".

A história de vida enunciada por Douglas torna-se "nada": presenciar o assassinato da mãe, ser encaminhado para a Febem pelo próprio pai, não 
saber ler ou escrever, não conhecer dinheiro, ir somente a um dia de aula, ter sido jogado na rua pela tia, tudo isto é "nada". Uma vez que a subjetividade não pode ser dissociada das vivências de uma pessoa, Douglas ocupa uma nova posição de sujeito: "nada". Portanto, tudo o que lhe aconteceu ou vier a acontecer com ele é "nada". Douglas pode ser considerado assim, um ser abjeto ${ }^{3}$; que nasceu em 1969, mas teve sua certidão de nascimento lavrada apenas em 1992; que tem sua saúde mental avaliada e sua "insanidade" "decretada" através de um documento com cinco itens, cujas respostas somam 23 palavras, sem o CID (Classificação Internacional de Doenças) correspondente, por um médico que não se sabe quem é e qual sua especialidade.

A partir de sua posição de sujeito "nada", "abjeto", ninguém melhor para ser curadora de Douglas do que a pessoa que o trata como "merece": a tia que o "jogou na rua". Dessa forma, pode-se compreender porque, ao tentar oferecer resistência denunciando a tia para o Ministério Público e, mais tarde, ao tentar ser ouvido pela Promotora de Justiça oito anos depois de decretada sua interdição e curatela, Douglas não pode sequer, entrar em seu gabinete. Como abjeto que é, sua exclusão precisa ser concreta, ele precisa ficar fora: fora do rol dos "nascidos", fora da escola, fora de casa, fora da sala da Promotoria. Ser-lhe designada a posição de sujeito "demente", pode ser considerado, assim, como algo de positivo, ainda que continue remetendo-o à exclusão, pois que foi a "melhor" posição de sujeito que lhe restou. Ele só pode estar "dentro", se for dentro da clínica psiquiátrica ou do CAPS, lugares a serem ocupados pelos "dementes", fabricados pelos dispositivos médico-jurídicos nos exames periciais.

A fim de se analisar a quais enunciados os diagnósticos mencionados podem associar-se e/ ou articular-se, é necessário retomar as primeiras páginas dos autos de seu processo, nas quais a Defensoria Pública requer a sua "Interdição e Curatela". No documento, pode-se ler:
O Paciente sofre de doença mental e seus atos do cotidiano revelam incapacidade para reger sua própria pessoa e administrar seus bens [...] O Promovente antecipa a apresentação dos quesitos ao Dr. Perito, na seguinte ordem: [...] 2 - O Paciente apresenta alguma anomalia mental? [...] 4 -A doença é reversível? [...] deverá a presente ser processada e, a final, julgada procedente, decretada a interdição de Douglas, e lhe nomeando Curador o próprio Promovente (Grifos da autora).

Nota-se que são estas enunciações do Defensor Público que embasarão os dois principais documentos dos autos do processo, respectivamente, o "Parecer do Ministério Público" e a decisão judicial, e não os diagnósticos enunciados no "laudo pericial": "distúrbios psiquiátricos", "deficiência mental (oligofrenia)" e "psicose esquizofrênica". Estes enunciados do suposto médico perito, ao se associarem aos "Quesitos" da Defensoria Pública, são capturados pelo discurso jurídico a fim de respaldarem-no, como se pode constatar pelos excertos de documentos ao longo dos autos do processo: "De acordo com as conclusões contidas no laudo pericial de fls. 25, [...] padece de anomalia psíquica de caráter irreversível [...] Urge, pois, que se lhe dê quem o represente legalmente" (Promotor de Justiça) (Grifos da autora) e "Por outro lado, verifica-se que o interditando, que realmente sofre de anomalia psíquica, de caráter irreversível, conforme se depara no laudo pericial de fls. 25, precisa de ser-lhe nomeado curador" (Juiz de Direito) (Grifos da autora). Ressalta-se que, no "laudo pericial", não há menção a "anomalia psíquica”, este "diagnóstico" é uma derivação de "anomalia mental", enunciação da Defensora Pública, que consta já na fl. 03 dos autos do processo. Uma apropriação de Douglas a partir da enunciação de seu diagnóstico, realizada através da (des)apropriação do discurso médico, por parte do Judiciário, que remete ao caso de Pierre Rivière, segundo Riot in Foucault (2007):

\footnotetext{
${ }^{3}$ Abjeto, aqui, está sendo utilizado em analogia com o conceito de abjeção em Judith Butler que, ao trabalhar o sujeito e o sexo, afirma que os sujeitos são formados a partir de uma matriz excludente que exige a produção simultânea dos que ainda não são sujeitos, os seres abjetos. 'O abjeto designa aqui precisamente aquelas zonas 'inóspitas' e 'inabitáveis' da vida social, que são, não obstante, densamente povoadas por aqueles que não gozam do status de sujeito, mas cujo habitar sob o signo do 'inabitável' é necessário para que o domínio do sujeito seja circunscrito. Essa zona de inabilitabilidade constitui o limite definidor do domínio do sujeito; ela constitui aquele local de temida identificação contra a qual - e em virtude do qual - o domínio do sujeito circunscreverá sua própria reivindicação de direito à autonomia e à vida. Neste sentido, pois, o sujeito é constituído através da força da exclusão e da abjeção, uma força que produz um exterior constitutivo relativamente ao sujeito, um exterior abjeto que está, afinal, 'dentro’ do sujeito como seu próprio e fundante repúdio” (Butler, 2000).
} 
Aqui, onde os magistrados se detêm com insistência, os médicos permanecem calados; um mesmo fato converge para a crueldade ou para a alienação mental etc. Pensamos que estas seleções e estas interpretações não são unicamente a expressão de um certo nível de saber médico, ou o efeito do funcionamento da máquina judiciária; elas traçam a linha de confronto de dois tipos de discurso e, através deles, dois poderes: trata-se de saber quem, da instituição médica ou da instituição judiciária, apoderar-se-á de Rivière (Riot in Foucault, p. 257).

Assim, os diagnósticos médicos referentes a Douglas articulam-se em uma demonstração de poder, prevalecendo o discurso jurídico como enunciador de verdade acerca de sua "insanidade", "incapacidade" e "necessidade de ser interditado e de ter um curador". É importante enfatizar que o suposto "laudo" é um documento sem título, em papel timbrado do "Poder Judiciário do Estado de Minas Gerais”, com indicação da "Secretaria da Segunda Vara Cível"; dois carimbos que a identificam a vara; o número do processo; a palavra "Interditando" e, logo abaixo: "Quesitos apresentados pelo requerente". O suposto médico tem um pequeno espaço disponível para suas respostas manuscritas entre as perguntas digitadas/datilografas (?) no documento. A apropriação dos supostos diagnósticos de Douglas e do suposto saber da medicina está clara: o documento está pronto, o diagnóstico também, basta respaldá-lo, a fim de que se possa dar prosseguimento ao que já foi enunciado na fl. 02 dos autos do processo (A fl. 01 corresponde à capa do processo).

Nesse sentido, a citação de Taborda (Brasil, 2007), integrante do livro “A Banalização da Interdição Judicial no Brasil" no qual ele é apresentado como Chefe do Departamento de Ética e Psiquiatria Forense da Associação Médica Brasileira, ilustra apropriadamente a análise aqui proposta:

Certo dia, um juiz me perguntou, numa vara de família, em Porto Alegre, se eu não gostaria de fazer as perícias de interdição dos processos daquela vara. Respondi que não haveria problema algum. Ele me perguntou quanto eu cobraria, eu respondi um valor xis. Ele disse que a quantia era muito alta. E ele me disse o seguinte: "Isso é pró-forma. A pessoa vem a minha frente, e eu vejo que ela está completamente incapacitada. Estou olhando e vendo que ela está completamente incapacitada.
O laudo que você vai dar é apenas para preencher o requisito legal (Taborda in Brasil, 2007, p. 207).

Não há, compondo os autos do processo de Douglas, qualquer documento que se refira à idoneidade de sua curadora, como antecedentes criminais e/ou "Nada Consta" da Polícia, bem como pesquisa sobre processos judiciais referentes a ela. A única referência à sua idoneidade é a declaração de Douglas, de que ela o teria “jogado na rua”, mas, esta afirmação foi ignorada, como se pôde constatar na descrição do processo. Os únicos documentos que se referem à curadora são uma cópia da carteira de identidade que segue a uma "Declaração de Pobreza para Fins Judiciais", na qual se lê: "Declaro [...] que não possuo condições de arcar com as despesas processuais e honorários advocatícios, sem prejuízo do próprio sustento, e sendo pobre na condição legal, firmo a presente".

O fato de Douglas ter sido internado 15 dias antes do pedido de interdição e curatela, não pode ser desconsiderado como possibilidade de ter sido uma estratégia para enfatizar a necessidade da interdição e/ou do benefício social. Não se pode comprovar, pelos documentos que constituem os autos do processo, se Douglas já recebia o benefício de amparo social quando da entrada do pedido de interdição e curatela ou se o pedido de concessão de benefício se deu após este fato. Pode-se ler, no requerimento de desarquivamento do processo realizado pela tia de Douglas, o seguinte: "motivo de fato e de direito": [...] 2) - Entretanto, após receber os benefícios de Amparo Social do irmão, o Promovente desapareceu, não dando mais notícias, prejudicando o Beneficiário e o normal andamento do processo".

Acerca dessa prática de se requerer interdição judicial a fim de se receber o Benefício de Prestação Continuada, Silva (Brasil, 2007) em sua exposição na abertura da "Audiência Pública" cita que, muitas vezes, os funcionários do Instituto Nacional do Seguro Social (INSS) afirmam que colaboram na "agilização" de processos de interdição para facilitar o acesso ao benefício. Assim como, segundo ele, em serviços de saúde mental, o diagnóstico acaba cedendo diante das condições socioeconômicas dos usuários e emitem-se laudos nos quais se atesta a incapacidade para os atos da vida civil, o que acaba por ser um contrassenso, pois, ao se despolitizar a situação, o agente do Estado concorre para desabilitar a cidadania do usuário. Tem-se assim, um problema de direitos humanos, pois se troca o benefício pela cidadania. $\mathrm{O}$ expositor aponta para: 
[...] a dinâmica judiciária que banalizou a concessão da interdição judicial sem que o que foi previsto em lei, do ponto de vista do controle das situações dos curatelados seja exercido, sem que exista uma fiscalização, uma pró-curação em relação ao acompanhamento desses curatelados que, podemos afirmar com certeza, pelos inúmeros casos que nossa experiência assistencial demonstra, são pessoas que, muitas vezes, não são beneficiárias dos recursos que recebem (Silva in Brasil, 2007, p. 24).

Esta citação se aplica ao caso de Douglas, pois não há a presença de documentos nos autos do processo que comprovem qualquer menção às seguintes possibilidades previstas em lei: (1) cabe recurso à interdição; (2) há obrigatoriedade de prestação de contas por parte do curador; (3) é preciso haver o levantamento de possíveis bens ou numerário do interditando durante o processo de nomeação de curador; (4) possíveis dívidas do interditando para com o curador devem ser explicitadas no processo; (5) se houver possibilidade de cura, é responsabilidade do curador procurar tratamento adequado para o interdito; (6) cessando a causa que determinou a curatela, há possibilidade de se pedir seu levantamento e (7) o curador pode ter suas funções suspensas em caso de extrema gravidade, quando se nomeia curador substituto interino. Uma vez que não foram explicitadas as obrigações legais e os compromissos da curadora no processo referente a Douglas, e, especialmente, não foram mencionadas as possibilidades de revisão e levantamento (suspensão) da curatela, o que se teve como efeito, está além da interdição de seus atos da vida civil. Da mesma forma, a nomeação de sua curadora teve como efeito, consequências muito além da nomeação de alguém que pudesse representá-lo. Os efeitos produzidos pelo processo de Douglas são a interdição do exercício de sua cidadania e a nomeação de alguém autorizado legalmente a exercer poder extremo e irrestrito sobre ele, uma vez que não tem obrigação de prestar conta de seus atos e tem "mandado" indefinido; como se houvesse uma transferência da cidadania de Douglas para sua curadora que, assim "inflada" de direitos e sem deveres, torna-se soberana. Quem, se não rei ou rainha pode, legitimamente, exercer poder irrestrito com um único dever de "cuidar de seu povo"? Quem, se não a realeza, tem a possibilidade de continuar exercendo poder a despeito de seus abusos e maus-tratos, com a probabilidade ínfima de ser destituído, como se verificou no caso de Douglas?

É, portanto, no âmbito da cidadania, que também se pode explicar a afirmativa da operadora do direito que deu título a este artigo: "Não converso com demente". Uma vez que o Judiciário trabalhou para legitimar possibilidades de exercício de poder irrestrito da curadora, fazendo retornar, em plena República, o poder soberano, também o MP nega a cidadania de Douglas. Foi suficiente, como descrito na introdução deste artigo, conversar com a "curadora-soberana" que negou seu despotismo, esvaziando as denúncias realizadas através do CAPS. Basta sua palavra, já que seu súdito é "demente", pois só um "demente" poderia imaginar desafiar o poder régio a que está submetido, especialmente a uma instituição que se erigiu em torno dele, como afirma Foucault ${ }^{4}$ (2005). Todos se curvam à soberania, logo, Douglas e os profissionais que o atendem devem, também, se curvar.

Os elementos presentes no processo de Douglas, ou talvez, seja melhor afirmar - os elementos não presentes no processo de Douglas permitem constatar que permanece a articulação entre o direito público e o princípio da soberania. Sua interdição é o resultado de um processo que lhe negou a condição de cidadão reiteradamente, tendo sido designada a ele a posição de sujeito "nada" e tendo culminado com a curatela plena sobre seus direitos civis sem que se questionasse a quem eles estavam sendo delegados.

\section{Considerações finais}

Os psicólogos não podem se furtar ao debate na arena política, restringindo-se a práticas e fazeres cotidianos que não considerem a amplitude do cenário em que as relações psicossociais se estabelecem. Trabalhar na saúde mental implica o compromisso

\footnotetext{
${ }^{4} \mathrm{O}$ princípio geral que norteou as análises de Foucault sobre as relações entre o direito e o poder foi o de que o pensamento jurídico foi elaborado para servir de instrumento ou justificação para o poder régio, sendo o personagem central do edifício jurídico ocidental o rei. Assim, desde a Idade Média, o papel essencial da teoria do direito foi o de fixar a legitimidade do poder. Toda a teoria do direito se organizou em torno do problema da soberania: seus direitos legítimos e a obrigação legal de obediência, que se traduz no problema da sujeição e da dominação, nos estudos de Foucault. O veículo para as relações de dominação e de técnicas de sujeição é o sistema do direito e o campo judiciário, o que torna necessário o exame do direito a partir dos procedimentos de sujeição que ele põe em prática (Foucault, 2005).
} 
ético de constante reflexão acerca das vidas que se colocam, de certa forma, sob nossa responsabilidade, e a obrigação de rejeitar a "naturalidade" de certas condições a que os portadores de transtorno mental são submetidos, como a exclusão e a estigmatização.

Assim, a Psicologia se pôs em campo, lançando-se em uma seara de difícil e desafiadora compreensão: a do direito. As análises apresentadas nesse artigo fazem ver e fazem falar da lacuna existente entre as práticas judiciárias e os princípios preconizados pela Reforma Psiquiátrica brasileira, especialmente, no tocante à inclusão social dos portadores de transtorno mental como sujeitos de direitos e deveres; o âmbito da cidadania.

O exercício do poder da justiça, no âmbito da cidadania dos portadores de transtorno mental, evoca ora a antiga relação entre a organização do direito em torno da soberania, como problematizado por Foucault (2005), com a fixação da legitimidade do poder e a obrigação legal da obediência resultante da possibilidade do exercício pleno de poder do curador em relação ao interdito, ora a sua subjugação, culminando com a relativização do exercício da cidadania por parte do portador de transtorno mental frente ao Estado.

O discurso jurídico, articulando-se com o saber médico, fabrica verdades acerca dos portadores de transtorno mental, sendo que os dispositivos médico-jurídicos "laudos", produzidos nos "exames periciais", operam como "álibis" para o exercício

\section{Referências}

Albuquerque, J. A. G. (1986). Instituição e poder: a análise concreta das relações de poder nas instituições. (2a ed.). Rio de Janeiro, RJ: Graal.

Brasil. (2007). Congresso Nacional. Câmara dos Deputados. Comissão de Direitos Humanos e Minorias. A banalização da interdição judicial no Brasil: relatórios. Brasília, DF: Câmara dos Deputados.

Brasil. (2010). Congresso Nacional. Senado Federal. Anteprojeto de Código de Processo Civil. Recuperado de http://www.senado.gov.br/novocpc/pdf/ anteprojeto.pdf

Brasil. (1916). Lei no 3.071, de $1^{\circ}$ de janeiro de 1916. Código Civil dos Estados Unidos do Brasil. Diário Oficial da União, 5 jan. 1916.

Brasil. (1973). Lei $n^{\circ}$ 5.869, de 11 de janeiro de 1973. Institui o Código de Processo Civil. Diário Oficial da União, 27 jul. 2006. de poder da justiça, respaldando cientificamente verdades enunciadas pelo Poder Judiciário.

As posições de sujeito em que os portadores de transtorno mental figuram como sujeitos ativos lhes são destituídas, resultando em posições de sujeito que remetem à passividade e consequente subjugação. Tentativas de resistência e exercício de poder por parte de portadores de transtorno mental, no jogo de forças com o Poder Judiciário, são inviabilizadas, não sendo possível ocupar outras posições de sujeito que não as que o discurso jurídico lhes designa.

Entende-se que a relevância desse artigo reside no fato de demonstrar um distanciamento entre as diretrizes da Reforma Psiquiátrica Brasileira e as práticas da justiça, enfatizando a necessidade da Psicologia contribuir para o debate que proporcione uma maior aproximação entre o direito e as ciências psi, hoje fundamentalmente representadas pela psiquiatria, no âmbito judicial. Entretanto, ressalta-se como limitação da pesquisa, que as análises aqui apresentadas não podem ser generalizadas para outros documentos da mesma natureza ou outros contextos que não o da comarca onde o CAPS referido está localizado. Há a necessidade de que outras pesquisas articulando o direito e a saúde mental sejam realizadas a fim de que essa intersecção possa ser melhor compreendida, permitindo um amplo debate acerca do tema, cada vez mais presente no cotidiano dos serviços de saúde mental.

Brasil. (2001). Lei no 10.216, de 6 de abril de 2001. Dispõe sobre a proteção e os direitos das pessoas portadoras de transtornos mentais e redireciona o modelo assistencial em saúde mental. Diário Oficial da União, 9 abr. 2001.

Brasil. (2002). Lei $n^{\circ}$ 10.406, de 10 de janeiro de 2002. Institui o Código Civil. Diário Oficial da União. 11 jan 2002.

Butler, J. (2000). Corpos que pesam: sobre os limites discursivos do "sexo". In: Louro, G. L. (org.) O corpo educado: pedagogias da sexualidade. (2a. ed.) (pp. 110-127). Belo Horizonte, MG: Autêntica.

Foucault, M. (1996). A verdade e as formas jurídicas. Rio de JJaneiro, RJ: Nau Editora. (Original publicado em 1973).

Foucault, M. (2005). Em defesa da sociedade. São Paulo: Martins Fontes. (Original publicado em 1999).

Foucault, M. (2007). Eu, Pierre Rivière, que degolei minha mãe, minha irmã e meu irmão. (8a ed.). São Paulo, SP: Graal. (Original publicado em 1977). 
Foucault, M. (2010). A arqueologia do saber. (7a ed.). Rio de Janeiro, RJ: Forense Universitária. (Original publicado em 1969).

Instituto Franco Basaglia (2004). Conversando com o Ministério Público: o Ministério Público e a reforma psiquiátrica. Rio de Janeiro, RJ: o autor.

\section{Sandra Maciel de Carvalho}

Mestre pela Universidade Federal de Juiz de Fora, Juiz de Fora - MG. Brasil.

E-mail: sandramacielpsi@gmail.com

\section{Juliana Perucchi}

Doutora. Docente da Universidade Federal de Juiz de Fora, Juiz de Fora - MG. Brasil.

E-mail: juliana.perucchi@uff.edu.br
Endereço para envio de correspondência: Prefeitura Municipal de Cataguases, CAPS Centro de Atenção Psicossocial

Av. Astolfo Dutra, 334. Centro. CEP: 36770-000.

Cataguases - MG. Brasil.

Recebido 17/09/2014

Reformulado 28/11/2015

Aprovado 02/08/2016

Received 09/17/2014

Reformulated 11/28/2015

Approved 08/02/2016

Recibido 17/09/2014

Reformulado 28/11/2015

Aceptado 02/08/2016

Como citar: Carvalho S. M., \& Perucchi, J. (2016). “Não Converso com Demente”: intersecções entre direito e saúde mental. Psicologia: Ciência e Profissão, 36(3): 584-596. doi: 10.1590/1982-3703001332014

How to cite: Carvalho S. M., \& Perucchi, J. (2016). "I don't talk to lunatics": intersections between law and mental health. Psicologia: Ciência e Profissão, 36(3): 584-596. doi: 10.1590/1982-3703001332014

Cómo citar: Carvalho S. M., \& Perucchi, J. (2016). "No hablo con dementes": intersecciones entre el derecho y la salud mental. Psicologia: Ciência e Profissão, 36(3): 584-596. doi: 10.1590/1982-3703001332014 